\title{
Congenital Heart Diseases Diagnosed on Transthoracic Echocardiography: Perspectives from the University of Maiduguri Teaching Hospital, Nigeria
}

\author{
Faruk Buba ${ }^{1,2}$, Mohammed A. Talle ${ }^{1,2 *}$, Charles O. Anjorin'2, Mohammed M. Baba1,3, \\ Bello A. Ibrahim ${ }^{4}$ \\ ${ }^{1}$ Department of Medicine, College of Medical Sciences, University of Maiduguri, Maiduguri, Nigeria \\ ${ }^{2}$ Cardiology Unit, Department of Medicine, University of Maiduguri Teaching Hospital, Maiduguri, Nigeria \\ ${ }^{3}$ Federal Medical Centre, Nguru, Nigeria \\ ${ }^{4}$ Department of Paediatrics, University of Maiduguri Teaching Hospital, Maiduguri, Nigeria \\ Email: ^abdultalle@yahoo.com
}

How to cite this paper: Buba, F., Talle, M.A., Anjorin, C.O., Baba, M.M. and Ibrahim, B.A. (2017) Congenital Heart Diseases Diagnosed on Transthoracic Echocardiography: Perspectives from the University of Maiduguri Teaching Hospital, Nigeria. World Journal of Cardiovascular Surgery, 7, 55-65.

https://doi.org/10.4236/wjcs.2017.74007

Received: December 19, 2016

Accepted: April 25, 2017

Published: April 28, 2017

Copyright $\odot 2017$ by authors and Scientific Research Publishing Inc. This work is licensed under the Creative Commons Attribution International License (CC BY 4.0).

http://creativecommons.org/licenses/by/4.0/

\begin{abstract}
In a retrospective study of 1224 transthoracic echocardiograms performed between January 2011 and December 2013, we evaluated the spectrum of congenital heart disease (CHD) diagnosed at a tertiary referral centre in Maiduguri, north-eastern Nigeria. Diagnosis of CHD was made in $88(8.3 \%)$ subjects, comprising $23(26.1 \%)$ adults and $65(73.9 \%)$ aged less than 18 years. Forty six (52.3\%) of those with CHD were females, while $42(47.7 \%)$ were males. The frequencies of the CHD in decreasing order were: ventricular septal defect 23 (26.1\%), tetralogy of Fallot (TOF) 14 (15.9\%) and atrial septal defect (ASD) and atrioventricular septal defect (AVSD) were 11 (12.5\%) each. One of the patients with AVSD had Ellis Van Creveldt syndrome. Six (6.8\%) cases of patent ductus arteriosus (PDA) were diagnosed in those younger than 18 years, while all the $5(5.7 \%)$ cases of Ebstein's anomaly were diagnosed in adults. There were $6(6.8 \%)$ cases of Eisenmenger syndrome involving three cases of AVSD, one case of ASD and two cases of Ebstein's anomaly. Timely definitive cares for these patients are still lacking in Nigeria and many areas of sub-Saharan Africa. We recommend sensitization of all relevant clinicians to actively look for congenital heart defects. Pulse oximetry and postnatal echocardiographic new-born screening which were previously validated should be implemented at secondary and tertiary levels, and efforts should be made towards providing the needed care for patients with CHD.
\end{abstract}

\section{Keywords}

Congenital Heart Disease, Transthoracic Echocardiography, Nigeria 


\section{Introduction}

Studies on the burden of cardiovascular disease in sub-Saharan Africa revealed hypertension-related cardiovascular disorders, rheumatic heart disease and dilated cardiomyopathy (including peripartum cardiomyopathy) as the dominant aetiologies [1] [2] [3]. However, studies, especially in paediatric age-groups reported high prevalence of congenital heart diseases [4] [5] [6]. In general, CHD occurs in about $0.8 \%$ of neonate, taking the lead as the most common inborn defect [7].

The successes recorded in paediatric surgery and care of patients with CHD over the years have resulted in large number of these patients surviving into adulthood, giving rise to the budding sub-speciality of Adult Congenital Heart Disease (ACHD), otherwise, known as Grown Up Congenital Heart (GUCH) [8]. The transformation experienced by these survivors results mainly from reparative and palliative operations, with the attendant risks of reoperations, cardiac arrhythmias, heart failure and premature death [9]. Majority of patients with CHD in sub-Saharan Africa have no access to surgery. Consequently, many pass through the natural history of their diseases with the attendant mortality in infancy or early childhood and morbidity in adulthood. The plethora of modalities employed in cardiology complements each other in achieving a comprehensive evaluation of CHD, with each modality having its merits and demerits [10]. Although cardiac magnetic resonance imaging and multi-sliced cardiac tomography are assuming greater roles in evaluation of cardiac structure and function, echocardiography remains in the fore front of the initial assessment of patients with CHD owing to its advantages of low cost, portability, ease of use, accuracy and reproducibility [11]. Even though the burden of CHD has been variously reported from different parts of Nigeria [4] [5] [12], there are no such reports from the north-eastern part of the country with a population of close to 30 million people. Additionally, most of the reports are in paediatric age groups. The aim of the study was to determine the spectrum of CHD diagnosed in adults and paediatric patients using transthoracic echocardiography at the University of Maiduguri Teaching Hospital.

\section{Methods}

We studied the echocardiographic data of patients that underwent transthoracic echocardiography at the University of Maiduguri Teaching Hospital from January 2011 to December 2013. Echocardiography was performed with MyLab 50CV (Esaote) and Siemens Acuson X300 (Siemens), both equipped with variable frequency transducers. Images were obtained using M-mode, 2D-mode, color flow, and Doppler modalities from the standard echocardiographic windows (as well as subcostal and suprasternal windows), adhering to the ASE guideline [13]. Congenital heart disease (CHD) was usually assessed in the division using the sequential segmental approach (European approach on account of the promoters of the original concept) [14]. Different modifications of the standard imaging planes were adopted as required for adequate characterization of 
lesions. Where necessary, a given diagnosis is adjudicated by at least two of the three cardiologists involved. Owing to lack of a paediatric cardiologist in our centre, paediatric echocardiography is carried out by adult cardiologists in line with recommendations of the guideline on paediatric echocardiography [15]. Images are routinely copied onto CD/DVD for archiving. Descriptive statistics was used in describing the different spectrum of echocardiographic diagnosis. Age was expressed as median [interquartile range] after confirmation of its nonparametric distribution using Kolmogorov-Smirnov test. Approval for the study was granted by the Research and Ethics Committee as part of the Heart Failure Registry.

\section{Results}

One thousand three hundred and two transthoracic echocardiograms performed over the 3-year period were available for review. Seventy-eights $(6.0 \%)$ were excluded due to poor image quality, inconclusive study, and incomplete data storage. Of the remaining 1224, 1058 (86.4\%) were abnormal. Diagnosis of CHD was made in $88(8.3 \%)$ subjects, comprising $23(26.1 \%)$ adults and $65(73.9 \%)$ aged less than 18 years. Forty six (52.3\%) of those with CHD were females, while 42 (47.7\%) were males. The median (interquartile range) age of the adult group was 30 (14) years, whilst those younger than 18 years had a median (interquartile range) age of 2 (8) years. Thirty-four (52\%) of patients less than 18 years were 2 years and below. The different forms of CHD diagnosed among the subjects are illustrated in Table 1 and Table 2. The most prevalent CHD was ventricular septal defect (VSD), observed in 23 (26.1\%) subjects. Twenty (86.9\%) of the cases of VSD were diagnosed in those younger than 18 years. Ten $(43.5 \%)$ of

Table 1. Types of CHD diagnosed in subjects below 18 years of age.

\begin{tabular}{cccc}
\hline & Females $(\mathrm{n}=35)$ & Males $(\mathrm{n}=30)$ & Total $(\mathrm{n}=65)$ \\
\hline Ventricular septal defect & $9(13.9)$ & $11(16.9)$ & $20(30.8)$ \\
Tetralogy of Fallot & $6(9.2)$ & $3(4.6)$ & $9(13.9)$ \\
Atrial septal defect & $2(3.1)$ & $5(7.7)$ & $7(10.8)$ \\
Atrioventricular septal defect & $6(9.2)$ & $3(4.6)$ & $9(13.9)$ \\
Patent ductus arteriosus & $2(3.1)$ & $4(6.2)$ & $6(9.2)$ \\
Pulmonary stenosis & $2(3.1)$ & $1(1.5)$ & $3(4.6)$ \\
Transposition of great arteries & $1(1.5)$ & $1(1.5)$ & $2(3.1)$ \\
IASA & $1(1.5)$ & $1(1.5)$ & $2(3.1)$ \\
Tricuspid atresia & $1(1.5)$ & $0(0)$ & $1(1.5)$ \\
Cotriatriatum & $1(1.5)$ & $0(0)$ & $1(1.5)$ \\
Cotriatriatumdexter & $2(3.1)$ & $0(0)$ & $2(3.1)$ \\
Univentricular heart & $0(0)$ & $1(1.5)$ & $1(1.5)$ \\
Aortic stenosis & $1(1.5)$ & $0(0)$ & $1(1.5)$ \\
Cleft mitral valve & $1(1.5)$ & $0(0)$ & $1(1.5)$ \\
\hline
\end{tabular}

IASA $=$ Interatrial septal aneurysm. All expressed as number (\%). 
Table 2. Types of CHD diagnosed in adults.

\begin{tabular}{cccc}
\hline & Females $(\mathrm{n}=11)$ & Males $(\mathrm{n}=12)$ & Total $(\mathrm{n}=23)$ \\
\hline Tetralogy of Fallot & $0(0)$ & $5(21.7)$ & $5(21.7)$ \\
Ebstein's anomaly & $3(13.0)$ & $2(8.7)$ & $5(21.7)$ \\
Atrial septal defect & $2(8.7)$ & $2(8.7)$ & $4(17.4)$ \\
Ventricular septal defect & $3(13.0)$ & $0(0)$ & $3(13.0)$ \\
Atrioventricular septal defect & $2(8.7)$ & $0(0)$ & $2(8.7)$ \\
Pulmonary stenosis & $1(4.3)$ & $1(4.3)$ & $2(8.7)$ \\
CCTGA & $0(0)$ & $1(1.5)$ & $1(1.5)$ \\
Coarctation of the aorta & $0(0)$ & $1(1.5)$ & $1(1.5)$ \\
\hline
\end{tabular}

CCTGA $=$ Congenitally corrected transposition of the great arteries. All expressed as number (\%).

VSD were classified as membranous, while 5 (21.7\%) were outlet VSD. There were $2(8.7 \%)$ cases each of inlet and muscular VSD, while the Gerbode type was reported in $1(4.3 \%)$ subject. There were $2(8.7 \%)$ cases of residual VSD after repair. Tetralogy of Fallot (TOF) was diagnosed in 14 (15.9\%) subjects, while atrial septal defect (ASD) and atrioventricular septal defect (AVSD) was each diagnosed in $11(12.5 \%)$ subjects. One of the subjects with TOF had extensive calcification of the aortic valves, resulting in AR, while another case of TOF was associated with PDA and pulmonary atresia. One case of ASD was associated with dilated coronary sinus. However, persistent left superior vena cava was not demonstrated with certainty. Six (6.8\%) cases of patent ductus arteriosus (PDA) were diagnosed in those younger than 18 years, while all the $5(5.7 \%)$ cases of Ebstein's anomaly were diagnosed in adults. The only case of coarctation of the aorta was diagnosed in a 45-year old male who presented with systemic hypertension, whilst congenitally corrected transposition of the great artery was diagnosed in a 400 level medical student who was being evaluated for palpitation. Images of some of the CHD diagnosed are illustrated in Figure 1 and Figure 2. Although detail of pulmonary pressure was not present in all cases, there were 6 (6.8\%) cases of Eisenmenger syndrome involving three cases of AVSD, one case of ASD and two cases of Ebstein's anomaly. One of the patients with AVSD had Ellis Van Creveldt syndrome (Figure 3).

\section{Discussion}

Congenital heart disease makes up the most prevalent cardiac problems in paediatric age group with prevalence ranging from 4 - 50/1000 live births [16] [17]. In Nigeria, the estimated incidence of CHD in the late 1960s was 3.5/1000 live births which was extrapolated from a study of 4200 consecutive births in Ibadan, south-western Nigeria and a recent study which recorded a prevalence of 4.6/1000 live births in Benin, south-south, Nigeria [18]. Similarly, Thomas et al., in a study in Lagos, south-western, Nigeria demonstrated 4.6\% rate of CHDs in autopsied bodies among paediatric age group patients. Our study found a frequency of 6.13 percent in patients below the age of 18 years. 


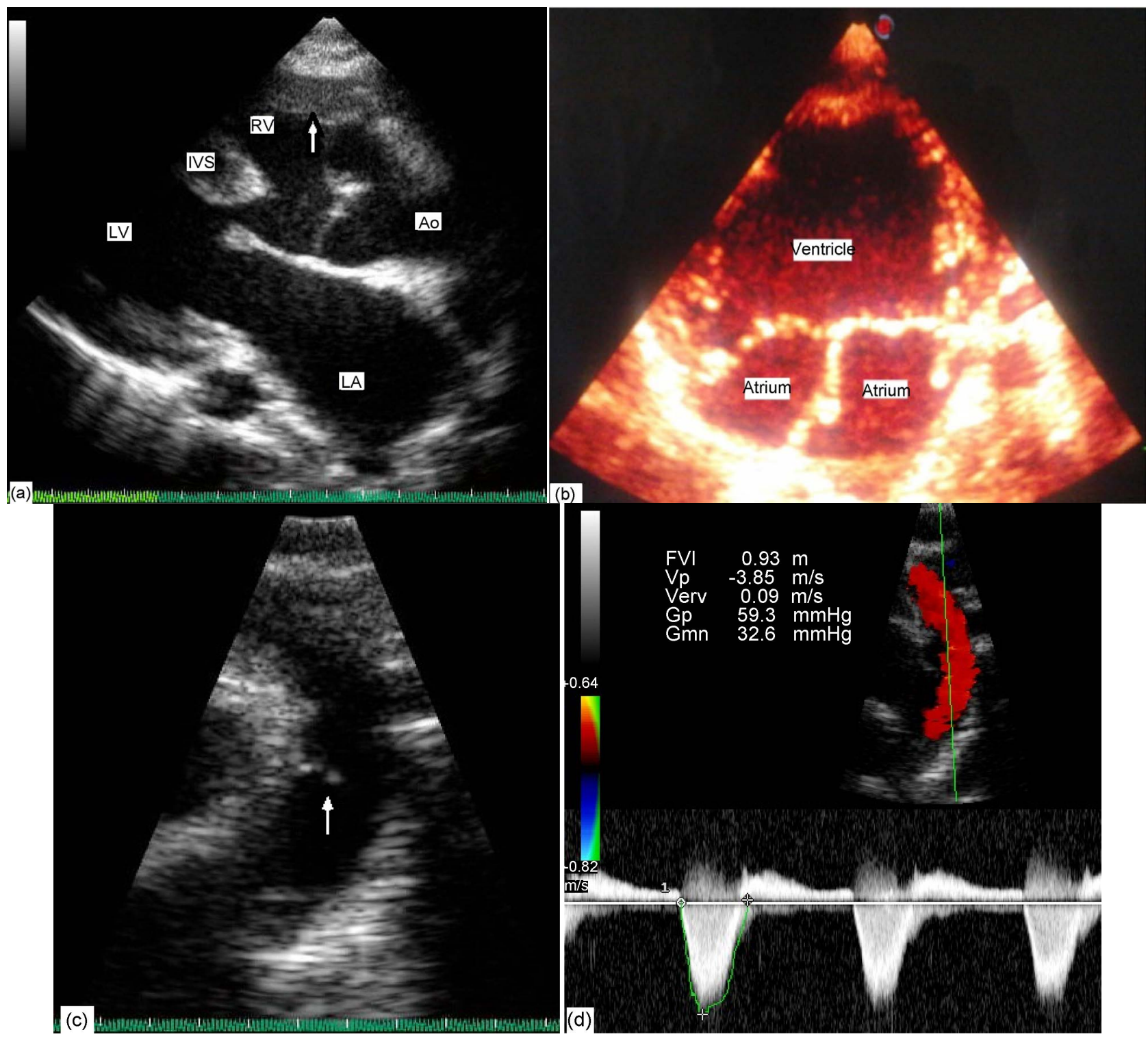

Figure 1. Showing ventricular septal defect, overriding of the aorta and right ventricular hypertrophy (arrow) in a patient with tetralogy of fallot (a); Univentricular heart (b); A transverse membrane (arrow) distal to the origin of left subclavian artery in a patient with coarctation of the aorta; continuous wave Doppler contour across the coarctation in (c) showing a peak velocity of $3.85 \mathrm{~m} / \mathrm{s}$ and associated gradients $(\mathrm{d})$.

In the Cameroun, a 4-year study period in patients suspected with cardiac diseases between the age of 2 months and 41 years revealed $13.1 \%$ of them had CHD [19]. In a survey conducted amongst public school children in Mozambique, Marijon, et al. found a prevalence of 2.3 in 1000 of which $80 \%$ were recently discovered [20]. In another African population, researchers in Angola, showed VSD and TOF as the most frequent acyanotic and cyanotic heart diseases constituting $30 \%$ and $8.6 \%$ respectively [21]. In the Middle East, Rahim et al. found a prevalence of 12.3 per 1000 live births with a variant pattern compared to other studies as ASD was more frequent followed by TOF, PDA, shunts and VSD in decreasing order [22]. Although there is paucity of data regarding grown-up CHD, eighty-five percent of patients with CHD are known to survive 

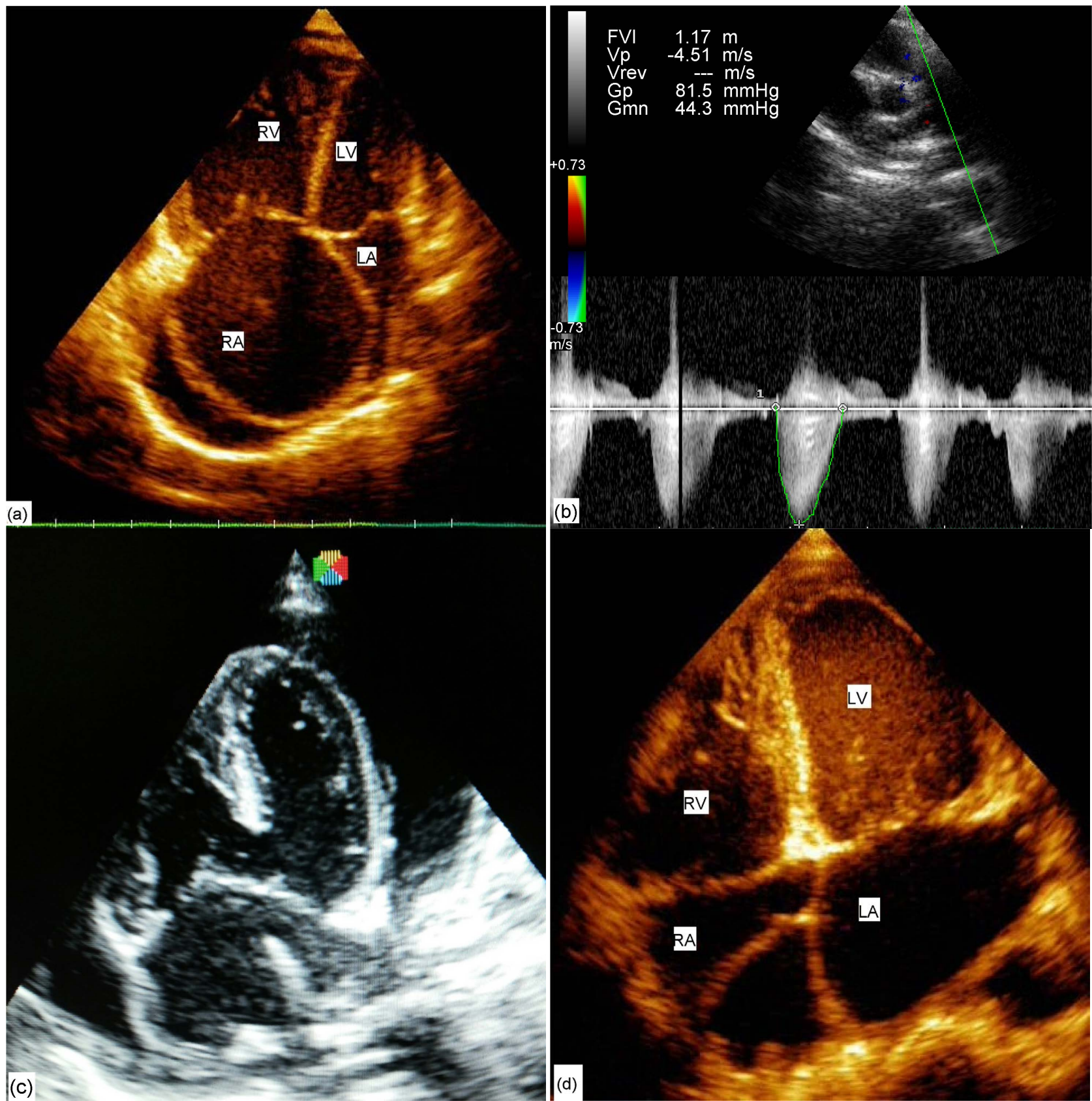

Figure 2. Dilated right atrium and right ventricle in a patient with pulmonary stenosis (a), continuous wave Doppler contour across the stenotic pulmonary artery showing a peak velocity of $4.5 \mathrm{~m} / \mathrm{s}$ and corresponding gradients (b); complete atrioventricular septal defect (c); and cortriatriatumdexter (d).

into adulthood [23].

The prevalence of CHD in our study reflected the documented finding in other studies with acyanotic CHD commoner than cyanotic CHD especially in patients below the age of 18 years [5] [6] [24]. The relative frequency of VSD was $43.8 \%$ of all CHDs especially in patients below the age of 18 years. VSD is the most common congenital heart defect in infants, occurring in $0.5 \%$ to $5 \%$ [25]. However, majority of VSDs, particularly non-membranuous type close spontaneously in approximately $80 \%$. Consistent with our study, Sani et al. [5] in Kano, 


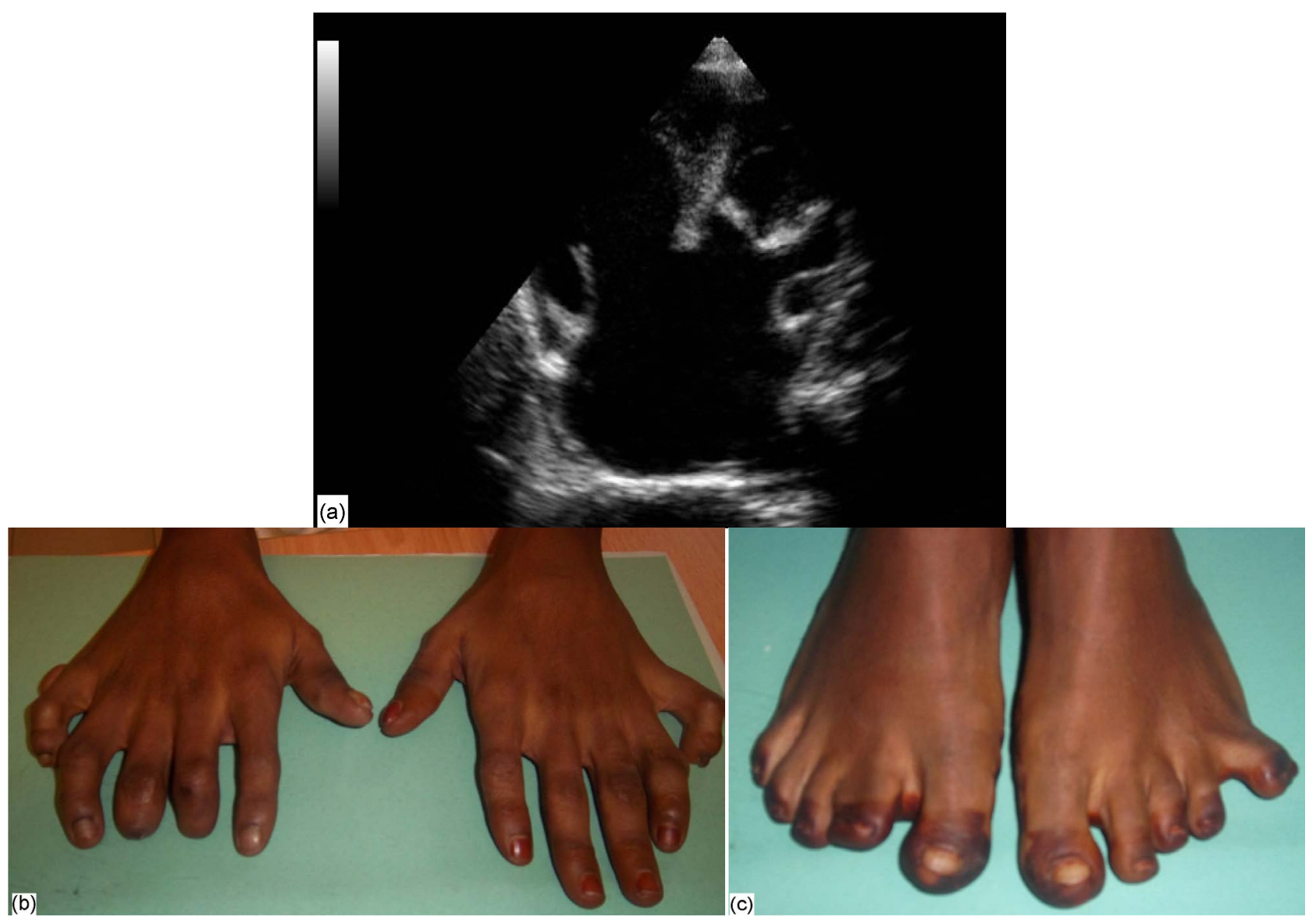

Figure 3. Atrioventricular septal defect (a) and associated limb deformities (b), (c) in a patient with Ellis Van Creveldt syndrome.

north-western Nigeria recorded 45.9\% while Sani UM et al. [24] from Sokoto, north-western Nigeria demonstrated a frequency of $41 \%$ of isolated VSD in their study group. Furthermore, Ibadin et al., in Benin, recorded a fairly similar frequency of 51 percent [12]. Within cases with isolated VSD, our series found membranous type as the commonest subtype accounting for $86.9 \%$ of VSD while the other subtypes were: outlet, inlet, muscular and Gerbode variant in decreasing order. The pattern was virtually similar in Kano as reported by Sani et al. [5].

The next most frequent defect demonstrated was TOF constituting $13.9 \%$ in patients below the age of 18 years and most frequent at par with Ebstein's anomaly in patients above the age of 18 years. TOF has its primary defect in the anterior deviation of the infundibular septum. It represents $5 \%-10 \%$ of all CHD and is the most common cyanotic cardiac diseases, with $5 \%$ of patients having an ASD constituting the pentalogy of Fallot [26]. The finding of TOF being the second commonest was similar to the study in Benin [12]. This is at odds with other previous studies demonstrating ASD and PDA as the most frequent in their series [22] [27]. PDA was the second commonest in some series, because the study groups were skewed by large proportions of preterm babies.

TOF and Ebstein's anomaly were tied commonest in patients above 18 years because of their probable attendance to hospitals due to cyanotic spells in the former and presentation as heart failure of the latter in adulthood. Ebstein's 
anomaly is an uncommon form of CHD constituting only $1 \%$ of congenital heart defects [28]. Its importance however, stem from the fact that $20 \%$ of patients may present with features of Wolff-Parkinson-White syndrome with the attendant sequelae of arrhythmias [19] [28]. One of our patients with Ebstein's anomaly had supraventricular tachycardia.

Eisenmenger syndrome (ES) is a form of pulmonary arterial hypertension $(\mathrm{PAH})$ related to congenital cardiac anomalies [29]. "Manifest" PAH is defined as a mean pulmonary artery pressure (mPAP) $>25 \mathrm{~mm} \mathrm{Hg}$ at rest, while $21-24$ $\mathrm{mm} \mathrm{Hg}$ as "borderline PAH" and $20 \mathrm{~mm} \mathrm{Hg}$ will be considered normal [30]. There is a lack of data regarding the prevalence of ES. However, a nationwide registry in Holland recorded a prevalence of 4.2 percent [31]. Six of our patients over the age of 18 years $(6.8 \%)$ had ES.

Ellis-van Creveld syndrome is a chondral and ectodermal dysplasia of autosomal recessive pattern, typified by short ribs, polydactyly, growth retardation and ectodermal and heart defects with few hundreds of cases reported worldwide [32]. Congenital defects occur in 50\% - 60\% of the subjects with most common being single atrium and a ventricular septal defect. Consistent with its rarity, we had one patient during our study period presenting with atrioventricular septal defect and associated limb deformities (Figure 3 ).

The pattern of gender differences in CHD was variedly reported in the literature. There was generally a male preponderance of both VSD and TOF among our patients, as reported in previous studies [5] [12]. However, females predominated in TOF below the age of 18 years as was shown in a previous study [24].

The pattern of CHD as seen at our tertiary centre is virtually similar with those from other centres. There is need to sensitize and re-train medical staff in various fields to actively search for CHD. The pulse oximetry screening program introduced for critical CHD is now recommended in the USA and need to be adopted in most centres to detect potential CHD early on [33]. Furthermore, widespread implementation of postnatal echocardiography may modify the prevalence, spectrum and sequelae of CHD from birth [34].

Our study has limitations inherent in most retrospective studies as exemplified by some missing data. Secondly, the findings cannot be extrapolated to mean the true burden of CHD in the populace since the majority may not access tertiary health care. Notwithstanding, the study has identified CHD as one of the major diagnoses among adults and those less than 18 years accessing echocardiography services at our centre.

\section{References}

[1] Moran, A., Forouzanfar, M., Samson, U., Chugh, S., Feigin, V. and Mensah, G. (2013) The Epidemiology of Cardiovascular Diseases in Sub-Saharan Africa: The Global Burden of Diseases, Injuries and Risk Factors 2010 Study. Progress in Cardiovascular Diseases, 56, 234-239. https://doi.org/10.1016/j.pcad.2013.09.019

[2] Ogah, O.S., Adegbite, G.D., Akinyemi, R.O., Adesina, J.O., Alabi, A.A., Udofia, O.I., et al. (2008) Spectrum of Heart Diseases in a New Cardiac Service in Nigeria: An Echocardiographic Study of 1441 Subjects in Abeokuta. BMC Research Notes, 1, 98. 
https://doi.org/10.1186/1756-0500-1-98

[3] Jing, A.M., Noubiap, J.J., Kamdem, P., WawoYonta, E., Temfack, E., KouamKouam, C., et al. (2013) The Spectrum of Cardiac Disease in the West Region of Cameroon: A Hospital-Based Cross-Sectional Study. International Archives of Medicine, 6, 44. https://doi.org/10.1186/1755-7682-6-44

[4] Sadoh, W.E., Uzodimma, C.C. and Daniels, Q. (2013) Congenital Heart Disease in Nigerian Children: A Multicentre Echocardiographic Study. World Journal for Pediatric and Congenital Heart Surgery, 4, 172-176. https://doi.org/10.1177/2150135112474026

[5] Sani, M.U., Mukhtar-Yola, M. and Karaye, K.M. (2007) Spectrum of Congenital Heart Disease in a Tropical Environment: An Echocardiographic Study. Journal of the National Medical Association, 99, 665-669.

[6] Thomas, M.O., Olusoji, O. and Awolola, N. (2013) Spectrum of Congenital Heart Disease in an African Population: A Necropsy Study. World Journal of Cardiovascular Diseases, 3, 34-39. https://doi.org/10.4236/wjcd.2013.31008

[7] Hoffman, J.I.E. (2013) The Global Burden of Congenital Heart Disease. Cardiovascular Journal of Africa, 24, 141-145. https://doi.org/10.5830/CVJA-2013-028

[8] Perloff, J.K. and Warnes, C. (2001) Congenital Heart Disease in Adults: A New Cardiovascular Specialty. Circulation, 84, 1881-1890 https://doi.org/10.1161/01.CIR.84.5.1881.

[9] Wren, C. and O'Sullivan, J.J. (2001) Survival with Congenital Heart Disease and Need for Follow Up in Adult Life. Heart, 85, 438-443 https://doi.org/10.1136/heart.85.4.438

[10] Houston, A., Hillis, S., Lilley, S., Richens, T. and Swan, L. (1998) Echocardiography in Adult Congenital Heart Disease. Heart, 80, S12-S26 https://doi.org/10.1136/hrt.80.2008.12s

[11] Alonso-Gonzalez, R. and Swan, L. (2013) Non-Invasive Imaging in Congenital Heart Disease. Heart, 10, 592-598.

[12] Ibadin, M.O., Sadoh, W.E. and Osarogiagbon, W. (2005) Congenital Heart Disease at the University of Benin Teaching Hospital. Nigerian Journal of Paediatrics, 32, 29-32.

[13] Lang, R.M., Bierig, M., Devereux, R.B., Flachskampf, F.A., Foster, E., Pellikka, P.A., et al. (2005) Recommendations for Chamber Quantification: A Report from the American Society of Echocardiography's Guidelines and Standards Committee and the Chamber Quantification Writing Group, Developed in Conjunction with the European Association of Echocardiography, a Branch of the European Society of Cardiology. Journal of the American Society of Echocardiography, 18, 1440-1463. https://doi.org/10.1016/j.echo.2005.10.005

[14] Anderson, R.H., Becker, A.E., Freedom, R.M., Macartney, F.J., Quero-Jimenez, M., Shinebourne, E.A., et al. (1984) Sequential Segmental Analysis of Congenital Heart Disease. Pediatric Cardiology, 5, 281-287.

[15] Lopez, L., Colan, S.D., Frommelt, P.C., et al. (2010) Recommedations for Quantification Methods during Performance of a Pediatric Echocardiogram: A Report from the Pediatric Measurements Writing Group of the American Society of Echocardiography Pediatric and Congenital Heart Disease Council. Journal of the American Society of Echocardiography, 23, 465-495. https://doi.org/10.1016/j.echo.2010.03.019

[16] Grabitz, R.G., Joffres, M.R. and Collins-Nakai, R.L. (1988) Congenital Heart Disese: Incidence in the First Year of Life. The Alberta Heritage Pediatric Cardiology Program. Journal of the American Society of Echocardiography, 128, 381-388. 
[17] Nembhard, W.N., Wang, T., Loscalzo, M. and Salemi, J.L. (2010) Variation in the Prevalence of Congenital Heart Defects by Maternal Race/Ethnicity and Infant Sex. Journal of Pediatrics, 156, 259-264. https://doi.org/10.1016/j.jpeds.2009.07.058

[18] Gupta, B. and Antia, A.U. (1967) Incidence of Congenital Heart Disease in Nigerian Children. British Heart Journal, 29, 906-909.

[19] Tantchou Tchoumi, J.C., Ambassa, J.C., Kingue, S., et al. (2011) Occurrence, Aetiology and Challenges in the Management of Congestive Heart Failure in Sub-Saharan Africa: Experience of the Cardiac Centre in Shisong, Cameroon. The Pan African Medical Journal, 8, 11.

[20] Marijon, E., Tivane, A., Voicu, S., et al. (2006) Prevalence of Congenital Heart Disease in Schoolchildren of Sub-Saharan Africa, Mozambique. International Journal of Cardiology, 113, 440-441. https://doi.org/10.1016/j.ijcard.2006.06.049

[21] Manuel, V., Morais, H., Manuel, A., David, B. and Gamboa, S. (2014) Ventricular Septal Defect in Children and Adolescents in Angola: Experience of a Tertiary Centre. Revista Portuguesa de Cardiologia, 33, 637-640. https://doi.org/10.1016/j.repc.2014.03.012

[22] Rahim, F., Ebadi, A., Saki, G. and Remazani, A. (2008) Prevalence of Congenital Heart Disease in Iran: A Clinical Study. Journal of Medical Science, 8, 547-552.

[23] Warnes, C.A., Williams, R.G., Bashore, T.M., et al. (2008) ACC/AHA 2008 Guidelines for the Management of Adults with Congenital Heart Disease. Circulation, 118, e714-e837. https://doi.org/10.1161/CIRCULATIONAHA.108.190690

[24] Sani, U.M., Jiya, N.M., Ahmed, H. and Waziri, U.M. (2015) Profile and Outcome of Congenital Heart Diseases in Children: A Preliminary Experience from a Tertiary Centre in Sokoto, North Western, Nigeria. Nigerian Postgraduate Medical Journal, 22, 1-8.

[25] Minnette, M.S. and Sahn, D.A. (2006) Ventricular Septal Defects. Circulation, 114, 2190-2197.

[26] Bashore, T.M. (2007) Adult Congenital Heart Diseases: Right Ventricular Outflow Tract Lesions. Circulation, 115, 1933-1947. https://doi.org/10.1161/CIRCULATIONAHA.105.592345

[27] Nikyar, B., Sedehi, M., Mirfazelli, A., Qurbani, M. and Golalipur, M.J. (2011) Prevalence and Pattern of Congenital Heart Disease among Neonates in Gorgan, Northern Iran (2007-2008). Iranian Journal of Pediatrics, 21, 307-312.

[28] AttenhoferJost, C.H., Connolly, H.M., Dearani, J.A., et al. (2007) Ebstein's Anomaly. Circulation, 115, 277-285. https://doi.org/10.1161/CIRCULATIONAHA.106.619338

[29] Kaemmerer, H., Mebus, S., Sculze-Neick, I., et al. (2010) The Adult Patient with Eisenmengersyndrome: A Medical Update after Dana Point: Part I: Epidemiology, Clinical Aspects and Diagnostic Options. Current Cardiology Reviews, 6, 343-355.

[30] Badesch, D.B., Champion, H.C., Sanchez, M.A., et al. (2009) Diagnosis and Assessment of Pulmonary Arterial hypertension. Journal of the American College of Cardiology, 54, S55-S66.

[31] Duffels, M.G., Engelfriet, P.M., Berger, R.M., et al. (2007) Pulmonary Arterial Hypertension in Congenital Heart Disease: An Epidemiologic Perspective from a Dutch registry. International Journal of Cardiology, 120, 198-204.

https://doi.org/10.1016/j.ijcard.2006.09.017

[32] Baujat, G. and Merrrer, L. (2007) Ellis-Van Creveld Syndrome. Orphanet Journal of Rare Diseases, 2, 27. http://www.OJRD.com/content/2/1/27

[33] Thangaratinam, S., Brown, K., Zamora, J., et al. (2012) Pulse Oximetry Screening 
for Critical Congenital Heart Defects in Asymptomatic Newborn Babies: A Systematic Review and Meta-Analysis. Lancet, 379, 2459-2464.

https://doi.org/10.1016/S0140-6736(12)60107-X

[34] Sadoh, W.E.U., Zodinma, C.C. and Daniels, Q. (2013) Congenital Heart Disease in Nigerian Children: A Multicenter Echocardiographic Study. World Journal for Pediatric and Congenital Heart Surgery, 4, 172-176.

https://doi.org/10.1177/2150135112474026

Submit or recommend next manuscript to SCIRP and we will provide best service for you:

Accepting pre-submission inquiries through Email, Facebook, LinkedIn, Twitter, etc. A wide selection of journals (inclusive of 9 subjects, more than 200 journals)

Providing 24-hour high-quality service

User-friendly online submission system

Fair and swift peer-review system

Efficient typesetting and proofreading procedure

Display of the result of downloads and visits, as well as the number of cited articles Maximum dissemination of your research work

Submit your manuscript at: http://papersubmission.scirp.org/

Or contact wjcs@scirp.org 